\title{
FEATURE
}

\section{How Do Our Students Learn? An Outline of a Cognitive Psychological Model for Information Literacy Instruction}

\section{Dani Brecher Cook and Kevin Michael Klipfel}

\section{Dani Brecher Cook (dani_cook@ cuc.claremont.edu) Information Literacy and Learning Technologies Coordinator, The Claremont Colleges Library, Claremont University Consortium, Claremont, California. Kevin Michael Klipfel (kklipfel@csuchico.edu) Head, Research, Teaching and Learning, Meriam Library, California State University-Chico.}

\section{Authors' contributions were equal; names are listed alphabetically.}

Reference \& User Services Quarterly, vol. 55, no. 1, pp. 34-41 (c) 2015 American Library Association. All rights reserved.

Permission granted to reproduce for nonprofit, educational use.
Effective pedagogy requires understanding how students learn and tailoring our instruction accordingly. One key element of student-centered pedagogy involves understanding the cognitive psychological processes according to which students learn, and to structure our teaching with these processes in mind. This paper fills in a gap in the current literature, by applying empirically grounded lessons drawn from the cognitive science of learning, and discussing specific applications of these lessons for information literacy instruction. The paper outlines a framework for information literacy instruction, grounded in the educational and cognitive psychology literature, for facilitating student retention and transfer of information literacy skills, two classic measures of student learning. Five specific principles and several strategies for promoting retention and transfer within information literacy instruction are outlined. This article is an expansion of a presentation given at LOEX in May 2014.

WHAT ARE THE GOALS OF AN INFORMATION LITERACY EDUCATOR?

Aristotle famously began his treatise on the good life, the Nicomachean Ethics, by drawing an analogy between the science of ethics and the art of archery. Just as archers are more likely to be successful if they clearly understand their target, searchers after ethical truth must have some theoretical understanding of the "good life" to aim their lives toward that goal. ${ }^{1}$ Without understanding the objective, achieving a goal is a matter of luck, not expertise and wisdom. Extending this analogy to pedagogy, instructors must have a clear idea of how and whether our students learn, so that they can adopt the most effective strategies for facilitating learning.

Applying insights from cognitive and educational psychology is one highly effective way educators can take concrete steps to successfully approach their teaching to maximize student learning. ${ }^{2}$ Within the educational psychology literature, "learning" has a very specific definition. Educational psychologists Mayer and Wittrock write that learning is "a change in the learner's knowledge."3 This change can be measured through outcomes of retention and transfer, two "classic measures" of student learning. ${ }^{4}$ Retention is "the ability on the part of the learner to remember, recognize, and recall information presented to them," while transfer is "the ability to take what one has learned in one situation and use it to solve problems in unrelated contexts." 5 
Understanding the science of learning is particularly important for instruction librarians in academic libraries who are being increasingly called upon to take on robust teaching and learning roles on their campuses. ${ }^{6}$ Although most information literacy (IL) instruction takes place within academic libraries, the goals are much broader. Librarians are not simply teaching students how to identify scholarly sources, access library databases, and cite sources. Instead, the instruction librarian's job is to teach students information literacy skills, applicable in contexts as varied as onthe-job decision-making and researching a new purchase. ${ }^{7}$ These objectives align directly with the concepts of retention and transfer: we want students to remember the concepts and skills that we teach them (retention), but we also want students to take what they have learned and apply it to new, unrelated contexts (transfer). Recent research suggests that IL instruction has mixed results in this regard, ${ }^{8}$ indicating a need for strategies to organize information literacy instruction in a way that will facilitate the transfer of IL skills acquired in one context (disciplinary research) to other contexts (other academic work, future careers, and personal needs).

A second key psychological idea about how people learn may come as a surprise to many educators given the ubiquitous practice of teaching to various "learning styles," especially within the library literature. ${ }^{9}$ A recent meta-analysis of the education research on learning styles research indicates that there is no compelling evidence for the claim that teaching with such preferences in mind enhances student learning. ${ }^{10}$ As a matter of fact, the cognitive psychological literature indicates that people "are more alike than different in how they learn"11 and that, from a cognitive standpoint, "[a]ll students do have certain things in common." 12 That is not to say that people do not have different learning preferences or interests; that learning disabilities are not real; or that some people may not be better than others at remembering certain types of information. ${ }^{13}$ Those statements are all certainly accurate; however, cognitive psychology has found that almost all human brains share important similarities in terms of how they absorb and process information. For education practitioners, this means that there are certain pedagogical strategies that can improve the likelihood of learning for most students. ${ }^{14}$ The framework proposed in the present paper leverages this insight to suggest ways that instruction librarians can improve student learning outcomes. With these two key psychological principles in mind, instruction librarians can focus their instruction around the following two general questions:

1. How can I teach this material to students so that it best facilitates their retention of the information being presented?

2. How can I teach this material to students so that it best facilitates their ability to transfer this information across domains?
This paper elaborates five general strategies, grounded in the cognitive and educational psychology literature, that can help answer these two questions for any instruction session (these principles also apply to digital learning objects created to teach students online). This theoretical, evidence-based understanding of learning can help instruction librarians focus their practice toward long-term outcomes applicable beyond one library session. It also allows for reflective practice and introspection, encouraging instruction librarians to examine what we teach, how we teach it, and why it matters. This cognitive model of instruction is intended to serve as a guide and inspiration for instruction librarians who want to engage in evidence-based practice and leverage the findings of cognitive science to improve student learning outcomes.

\section{FIVE PRINCIPLES FOR STRUCTURING INFORMATION LITERACY INSTRUCTION}

\section{Principle 1: Create a Problem Context}

Human beings and their primate relatives are innately tuned to enjoy solving problems. In a 1949 study, University of Wisconsin researchers discovered that rhesus monkeys did not (as the scientists expected) require external incentive to solve a basic mechanical puzzle; they enjoyed solving the puzzle simply for its own sake. ${ }^{15}$ Additional studies have confirmed that "solving a problem gives people pleasure."16 The introduction of a puzzle or a problem to be solved immediately grabs people's attention, as they perceive that there will be something interesting and worthwhile involved in the process. ${ }^{17}$

For this reason, organizing instruction around a concrete intellectual problem can be an effective way to increase student retention of information literacy skills. When students come to a library session with a particular assignment to work on, there is an immediate problem context raised: students need to gain the skills that will help them crack the puzzle that is their assignment. This provides a critical opportunity for instruction librarians. With learning outcomes explicitly tied to the skills required to complete an assignment, the session becomes immediately relevant to students and can increase motivation.

Increasing students' cognitive engagement has been demonstrated to increase their information retention. Indeed, the cognitive psychology literature also indicates that people tend to remember what they pay attention to. ${ }^{18}$ If people are inherently more likely to be interested in problems than a straight delivery of content, then it follows that organizing lessons around specific problems that relate to the assignment at hand can lead students to be more invested in what they are learning and to thus improve their retention of material. ${ }^{19}$

There are multiple strategies for applying a problem context to an IL session. By being explicit about the session's learning outcomes, librarians can define the problem context from the outset of the session and generate student interest. A librarian might write the targeted learning outcomes on the 


\section{FEATURE}

board and say something like, "The focus of this session will be to help you learn the research skills you'll need for your assignment." Students should then see the relevancy of the session to their current puzzle, completing the assignment.

Following the same lines, using the specific language of the assignment can increase cognitive engagement. For example, an instruction librarian might say of a specific learning outcome or skill: "This will help you find the three scholarly sources for your literature review," highlighting the relevant portion of the assignment prompt. This language clearly indicates that the session is directly relevant to students' coursework. By using the language of the assignment prompt, the librarian both taps into the student's instrumental motivation to successfully complete the assignment for a grade and provides a potential solution for the problem of the assignment.

This strategy not only promotes retention, but also creates ideal conditions for facilitating the transfer of information literacy skills to other contexts. By tying a more abstract concept to a real-life problem (e.g., finding scholarly research for an annotated bibliography), students gain conditional knowledge, "knowing when and why to use existing conceptual and procedural knowledge." ${ }^{20}$ The acquisition of conditional knowledge has been demonstrated to improve the likelihood of transfer. When students understand how and why a particular skill is relevant, they are better prepared to recognize structural similarities in other contexts which may look different on the surface, but in which the same knowledge applies.

\section{Principle 2: Do Less}

In most library instruction scenarios, ranging from one-shot sessions to curriculum-embedded mini-sessions, librarians have a limited amount of time to teach information literacy concepts and competencies. ${ }^{21}$ The temptation, then, is to pack as much content into a session as possible to maximize students' exposure to library resources and research skills. However, research in cognitive science indicates that this strategy is ineffective, and that by limiting the amount of content delivered in a single classroom session, instructors can improve the amount of information students retain.

In his seminal 1956 article, George A. Miller posited that the human brain can only successfully process a limited amount of new information at one time. ${ }^{22}$ While there is an ongoing debate in the psychological literature over the exact "magical number" of discrete items that can be processed by the brain at once, as well as controversy over whether there is a universal specific number at all, the general consensus is that there is some mental limit to absorbing new information. ${ }^{23}$ Miller's theory and related research create the basis for "cognitive load theory," which considers the balance between acquisition of new information, building connections to previously learned information, and problem solving. ${ }^{24}$

A related phenomenon is "information overload," which occurs when too much relevant information is presented to a person, to the point where they are unable to differentiate and prioritize information. ${ }^{25}$ When people are confronted with too much information to process, they turn to a variety of coping behaviors to limit information input (e.g., tuning out, satisficing). ${ }^{26}$

What we call "learning" begins when information enters the working memory, the part of the brain that "holds the stuff you're thinking about" and which is the site of the information processing that is addressed in cognitive load theory. ${ }^{27}$ For information to be learned it needs to travel from the working memory to the long-term memory, which stores facts and procedures for later recall. Simply put, this means that only information that fits into an individual's working memory has even a chance of being learned.

These limitations on how much new information a person can successfully process have direct implications for the classroom. Specifically, by targeting only two or three learning outcomes per instruction session, instructors can successfully direct students' focus to those skills and prevent the tuning out that occurs with information overload. By teaching less content, instructors can help students learn more.

One strategy for limiting the amount of content in a library session is to write down all potential outcomes for the session, given the particular assignment and infinite time. Then, rank the outcomes in order of priority: Which outcomes are the most critical for successfully completing the research assignment? The top two or three outcomes provide the basis for the current session. The remainder of the potential outcomes can form the basis of a compelling argument for additional library instruction sessions.

In short, minimizing content maximizes retention. Not only does limiting learning outcomes avoid cognitive overload, but it also provides time in the session for practice and application of new concepts. The importance of practice is discussed in Principle 5.

\section{Principle 3: Build a Narrative}

Human beings are innately interested in stories. ${ }^{28}$ Psychological research has shown that the human memory accords a special place to information presented in the form of a story; Willingham writes that "psychologists refer to stories as 'psychologically privileged,' meaning that they are treated differently in memory than other types of material." ${ }^{29}$ This uniquely human preference for stories is equally represented in the arts. For example, Joan Didion famously began her essay, "The White Album," by asserting, "We tell ourselves stories to live." ${ }^{30}$ Stories, then, are both humanistically and scientifically central to the human experience and memory. This insight gives teacher-librarians a concrete strategy for improving their pedagogy. When it is appropriate and necessary to offer explanations of class content to students, librarians can embed their instruction within the context of a narrative, since teaching through narrative maximizes the potential for learners to retain information.

There are at least two effective narrative strategies outlined in the literature that librarians can use; one which 
we will call narrative modeling, and a second which we will simply call storytelling. Narrative modeling is a strategy that instructors can use to teach students how to problem-solve for a particular intellectual task. Librarians tell the story of how they performed a research skill in a methodical, step-by-step manner. ${ }^{31}$ The story itself will vary depending on the stage of the research process. For example, if students are developing a research question, the instructor might, quite literally, tell the story of how they came to choose the example topic and describe how it fits within the context of the assignment. The instructor could then tell the story of how they searched for resources that met their information need.

For example, consider an assignment that asks students to write a music review in the style of a Pitchfork.com review. The librarian can then use class time to model the selection of a topic that fits within the confines of this assignment. Here is one possible narrative:

When I got your assignment, I thought about what I could write about, and I was thinking about writing about my favorite rapper, Drake. I wasn't sure exactly what to write about though, so I just started Googling "Drake," and came across this article from Vulture. com about Drake. ${ }^{32}$ It had this quote that I thought was really interesting: that what was unique about Drake, compared to other rappers, is that for him, rap "authenticity" isn't about being gangster, like it was for Jay-Z, but it's more about being yourself. So I thought that was really interesting: how Drake has changed authenticity in hip hop. It's not about like, being tough, or coming from the streets, but about just being yourself. So I asked myself, how would I turn that into a research topic about music and culture that I can actually find information on?

This explanation, embedded in the context of a story, can then be used to walk students through the process (again through narrative) for how they could go about developing keywords and searching for information that would satisfy this particular information need. This strategy can be used for any research assignment, and can be effective at any level throughout the curriculum, provided that the librarian is teaching to a specific assignment. Narratives will be unique to both the course assignment and the instructor herself; library instructors will want to choose examples that are authentic to themselves.

On the other hand, librarians are often asked to provide a general introduction to library research, without a specific assignment attached. This is often considered problematic in the literature, since, without a problem context for the library instruction session, students may lose interest, not pay attention to the librarian, and learn little in the process on than librarians are boring. ${ }^{33}$ However, librarians can take the opportunity to turn a "generic" instruction opportunity into a concrete narrative. This also creates a problem context for the session. For example,
When we do research in college, all we're doing is looking up something we might want to know more about. This is what your professors are doing, and it's what you can take the opportunity to use your classes for. There's so many things we see day-to-day that we don't even notice might be research, but that you could turn into a research project.

For example, I recently came across this article on Slate talking about "haters" ${ }^{34}$ — people who are always negative and down on people-and how scientific data now provides evidence for the popular phrase that "haters gonna hate."

Now I just thought this was kind of funny-but it's based on real research, and it's actually the kind of thing you could write a paper about-in a psychology class, in a first year writing course, or in many different places, really. But first you need to know a few research skills to be able to do that...

This method should not only be more interesting from a cognitive perspective than a more straightforward exposition, but it also provides students with a concrete model to solve information problems. As Mayer and Wittrock write, "The goal of example methods is to show learners how to solve typical problems in a field or subject area." ${ }^{35}$ Modelling such behavior through narrative presents the students with a meaning ful context to learn information literacy skills. This should help students retain and transfer these skills to their own information searching and research behaviors in the future.

A second narrative strategy that instruction librarians can use is a more straightforward storytelling approach. Educational psychologists Arya and Maul provide a concrete illustration of the difference between a traditional lecture and a storytelling narrative in the context of science education. ${ }^{36}$ For example, a straightforward expository lecture on Galileo's discoveries might look like this:

And with this simple, powerful tool [Galilean telescope], we can see many details when we use it to look up into the night sky. The moon may look like a smooth ball of light covered with dark spots, but on a closer look through this telescope, we can see deep valleys and great mountain ranges. Through the telescope, we can now see all the different marks on the moon's surface. ${ }^{37}$

This explanation, however, looks slightly different as a more traditional story:

When Galileo looked through his new telescope, he could see the surface of the moon, and so he began his first close look into space. He slept during the day to work and see the moon at night. Many people thought that the moon was a smooth ball with a light of its own. Now that Galileo had a closer look through 


\section{FEATURE}

his telescope, he realized that the moon's surface had mountains and valleys. ${ }^{38}$

The difference between the two modes of delivery is subtle, yet Arya and Maul's research indicates that the shift from lecture to story makes a significant difference for information retention. While educators have often stressed the "cognitive importance of having . . . texts students find interesting and relevant," ${ }^{39}$ it is interesting to note that how the material is presented by the instructor is at least as important as whether the material is deemed "inherently" interesting by students. The presentation of material matters.

Given this understanding of the science of memory, library instructors at all levels of experience now have a concrete, data-driven answer to the question, "How should I present this material to students so that they find it interesting?" The answer, though deeply humanistic, has the force of scientific evidence behind it: "Tell your students a story."

\section{Principle 4: Focus on Deep Structure}

As mentioned in Principle One, memory research indicates that people remember what they pay attention to. Practically, this means that librarians should organize their lessons around the material that they most want students to learn-the skills that are most important to retention and transfer. Additionally, the cognitive science literature can help librarians determine what aspects of a particular concept to focus instruction on. To more clearly understand this point, the distinction between shallow knowledge and deep knowledge is critical.

Shallow knowledge is a student's understanding of material that remains on the surface of the material and is therefore only useful within the initial context that it is learned. ${ }^{40}$ One simple example involves identifying an article of clothing. If one were to define a polo shirt as "that black shirt with the crocodile on it," that would be accurate in the immediate context in which it was learned. This description would accurately describe a single type of polo shirt-it would not describe all polo shirts, as some are not black and some do not feature a crocodile. It is superficial knowledge that is relevant only in one context and thus only informs choices within that single context. Without additional understanding, the knowledge is not transferrable and does not promote critical thinking.

In contrast, deep knowledge is knowledge that focuses on the core meanings_-or "deep structure" —of a practice. Deep structural knowledge is important because it is transferable to other contexts. It facilitates critical thinking by creating the right conditions for students to apply what they have learned in many situations. To return to the previous example, if we defined a polo shirt as "a form of shirt with a collar, a placket with typically two or three buttons, and an optional pocket, ${ }^{, 41}$ this would come much closer to providing deep structural knowledge of a polo shirt that would transfer to many contexts, and be useful for determining whether any type of shirt is a polo shirt. Unfortunately, a good deal of instruction that goes on in the classroom both in and outside of libraries focuses on superficial knowledge. This is problematic because it does not promote transfer and critical thinking, whereas getting students to think about meaning does promote those skills.

When thinking about teaching students the meaning, or deep structure, of material, it is often useful for the instructor to ask why it is important for the students to learn any given content. To take an example from the library context, consider database searching. Instruction pitched at surface level knowledge might focus on teaching students techniques for searching a particular database. This content is problematic from the standpoint of the science of learning, as it teaches students about a specific database, rather than about how databases work in general. It does not promote transfer and critical thinking, and thus does not lead to significant student learning.

Alternatively, a librarian might focus on teaching students the deep structural characteristics of databases. The librarian might ask herself: What is the point of teaching students about these databases in the first place? Why am I doing this? Reflecting on the deeper meaning of one's practice in this way may help the librarian to realize that the ultimate point of database instruction is not to tell students how to search this particular database, but to teach students more general principles about how databases work so that they can transfer this understanding to other databases. Although this point may seem banal, the implications for library instruction and particularly subject specialists may be radical, as it suggests that spending time showing students the ins and outs of a particular database is not an effective way for library instructors to spend time with students in the classroom. Instead, class time could be spent focusing on the deep structure of information, such as determining reliable evidence within a discipline. This strategy can help students ask deeper questions about the information they encounter in their daily lives. ${ }^{42}$

Deep structure can also apply to the so-called "popular" vs. "scholarly" source distinction. Why is teaching students this distinction important? What is the deeper meaning of the popular vs. scholarly dichotomy? The deeper meaning here is philosophical: Out of all the information available in the world, what should I believe? How do I know if it is reliable ${ }^{43}$ The core knowledge that librarians can teach to is what makes a piece of information trustworthy at its core. As Pashler et al. recommend, "[t]eachers should identify deep-level questions that they can use to prompt students to reason about underlying explanatory principles relating to the course content." ${ }^{\prime 4}$

Thinking of the popular vs. scholarly distinction in this way surfaces the deep structure behind the dichotomy: evidence. Belief should be based on the best available evidence, and the scholarly vs. popular article distinction is relevant because scholarly articles (at least tend to) provide the best 
evidence for the claims that an author makes. ${ }^{45}$ This is the deeper meaning of the popular/scholarly distinction and it is what we want our lesson to get students to think about. The meaning gets lost when the concept of evidence is not central to the lesson, as in general discussions of the CRAAP or other acronym-friendly tests that focus on surface characteristics of information. ${ }^{46}$

Information literacy librarians working with first-year students may simply introduce students to the concept of "evidence:" the idea that robust arguments are backed up with strong evidence, and that concept is what is practiced in research assignments. This can help scaffold information literacy instruction throughout the curriculum, with subject liaison librarians focusing on the concept of evidence within a discipline. In this way, instruction librarians can move away from pointing and clicking and toward helping students think critically about information. Of course, what counts as evidence within a particular subject (and even for a particular claim) area may vary. For example, business librarians may use their subject expertise to recognize that quality industry reports are the appropriate standard of evidence for a particular research assignment; history liaisons may recognize that primary sources are the kinds of evidence that matter to historians; and education librarians will realize that what counts as evidence in their area are quality, peer-reviewed studies about student learning. Subject expertise still matters. However, thinking about deep structure can change how liaison librarians frame their teaching. They can center a lecture explicitly on questions like "What counts as evidence in business?" which can help students engage meaningfully and deeply with information. Database instruction may be one part of an instruction session whose overall aim is more robust: to get student to deeply engage with information. One method instructors can use to facilitate this critical thinking capacity in students is to ask students questions that get at the deep structure of content. ${ }^{47}$

These examples are simply two concrete ways instruction librarians can organize their instruction around the deeper meaning of a particular research skill. Focusing instructional content on the deep structure of the material-the transferrable conceptual content at the core of a research practice-is rooted in the science of learning. The next question is how to get students to practice application of deep structure.

\section{Principle 5: Active Learning Is Practice of Deep Structure}

For something to be truly "learned," the information or process not only has to enter memory, but also has to get out again, to be applied to new contexts and situations. ${ }^{48}$ One of the most critical components of this process is practice. ${ }^{49} \mathrm{By}$ allowing time and creating opportunity to repeat and practice new knowledge in the classroom, instruction librarians can get students to actively engage with the deep structure of the material and thus be more likely to recall and use these new skills in novel contexts.
Deliberate practice means that individuals are motivated to focus on a task, put effort into improving their ability, find the task only slightly more difficult than what they are already capable of, and receive immediate and constructive feedback. ${ }^{50}$ This type of practice is required for a person to gain mastery of a concept or an entire domain. When Malcolm Gladwell writes about 10,000 hours of practice being required to become an expert in a field, he means 10,000 hours of deliberate practice. ${ }^{51}$ Indeed, this kind of intense focus on the task at hand is also what Willingham discusses when he says that people "remember what they pay attention to." For students to apply information literacy concepts in their research and beyond, instruction librarians need to facilitate this type of active engagement with the material in the classroom, helping students apply the research skills they will need to deliberately practice throughout their college careers.

The combination of practice and deep structure is a potent one for ensuring that students will learn the material. Practice facilitates retention, while deep structure facilitates transfer. Active learning exercises can combine these two ideas successfully. Meaningful active learning methods engage with higher-level cognitive activity, including exercises that require finding, evaluating, and using information. Students are asked to take concepts they learn in class and meaningfully engage with them. This is in contrast to more traditional teaching styles, such as lecturing.

Of course, many of the concepts discussed in information literacy are relatively abstract, such as reliability and credibility. However, this makes them excellent candidates for active learning exercises that engage with deliberate practice, as "the surest way to help students understand an abstraction is to expose them to many different versions of the abstraction." ${ }^{152}$ To engage with deep structure and practice, then, instructors need to plan classroom exercises that encourage students to think about the meaning of a concept in multiple different contexts.

To return to the polo shirt example from Principle 4, students who understand the deep structure of polo shirts will be able to identify any shirt as such that meets the general criteria: a placket, collar, and buttons. To have students practice their mastery of deep polo shirt structure, an instructor could have students examine a variety of types of shirts, including different brands, styles, and colors. Students would then have to pick polo shirts out of the line-up, correctly identifying them even when they featured different logos or colors than the original example shirt. This activity allows students to apply their knowledge in new contexts, and also to repeat the action of remembering and applying the concept of "polo shirt." This type of activity allows for both repetition and transfer.

By asking students to apply this new knowledge in multiple contexts, they begin to see the underlying themes of the polo shirt-that is, deep structure. Additionally, this approach calls for students to pull knowledge out of their memory, use it, and then return it. Another benefit 


\section{FEATURE}

of sustained deliberate practice is that "the more times you retrieve a memory ... the stronger it is and the more likely will remember it when you need to." ${ }^{53}$ Thus, when active learning activities involve practice focused on exposing deep structure, students are more likely to recall and reuse what they learn in library instruction.

\section{CONCLUSION}

Findings from the science of learning can refocus our instruction on student learning outcomes and enrich pedagogical practices. This cognitive model of instruction is intended to serve as a guide and inspiration for instruction librarians who want to engage in evidence based practice and leverage the findings of cognitive science to improve student learning outcomes. These five principles are broad enough that they can be applied to every type of information literacy session, including those done in online environments. The model is not meant to be prescriptive nor are the examples the sole way to apply these principles; indeed, one value of the framework as presented here is that it allows for infinite creativity in its applications. With this understanding in place, librarians are in the position to think of any number of innovative ways to develop specific learning exercises and lesson plans that will help students think about the deep structure of information within the context of research. This article should be the starting point for reflecting on how we teach and how we might support student learning more effectively.

To begin applying these five principles in your own instruction sessions, ask yourself:

- What research skills does this assignment require?

- Where will students be at in the research process during the time of the session?

- What two or three learning outcomes am I going to focus on?

- How can I incorporate storytelling into my lesson?

- What is the deep structure I want students to learn in the session?

- What active learning exercise would provide examples of the deep structure?

By answering these six questions, librarians will incorporate research findings that promote retention and transfer of information; that is to say, learning.

\section{References}

1. Aristotle, Nicomachean Ethics, ed. Sarah Broadie and Christopher Rowe (New York: Oxford University Press, 2002). I.2.

2. Terry Doyle and Todd Zakrajsek, The New Science of Learning: How to Learn in Harmony with Your Brain (Sterling, Virginia: Stylus Pub, 2013); John Dunlosky et al., "Improving Students' Learning With Effective Learning Techniques: Promising Directions From Cognitive and Educational Psychology," Psychological Science in the Public Interest 14, no. 1 (January 1, 2013): 4-58;
Harold Pashler et al., Organizing Instruction and Study to Improve Student Learning (Washington, DC: Institute of Education Sciences, U.S. Department of Education, 2007).

3. Richard E. Mayer and Merlin C. Wittrock, "Problem Solving," in Handbook of Educational Psychology, Second (New York: Routledge, 2006), 289.

4. Cf. Bransford et. al., who write that "the ultimate goal of learning is to have access to information for a wide set of purposes ... [so students can] transfer what they have learned in school to everyday settings of home, community, and workplace" $(1999,73)$

5. Mayer and Wittrock, "Problem Solving." 289.

6. Dani Brecher and Kevin M. Klipfel, "Education Training for Instruction Librarians: A Shared Perspective," Communications in Information Literacy 8, no. 1 (2014): 43-49.

7. Alison J. Head, Learning Curve: How College Graduates Solve Information Problems Once They Join the Workplace, Project Information Literacy Research Report, 2012.

8. Ibid.

9. See e.g., Angela Weiler, "Information-Seeking Behavior in Generation Y Students: Motivation, Critical Thinking, and Learning Theory," The Journal of Academic Librarianship 31, no. 1 (January 2005): 46-53.

10. Myron H. Dembo and Keith Howard, "Advice about the Use of Learning Styles: A Major Myth in Education," Journal of College Reading and Learning 37, no. 2 (Spr 2007): 101-9; Harold Pashler et al., "Learning Styles: Concepts and Evidence," Psychological Science in the Public Interest 9, no. 3 (December 2009): 105-19; Frank Coffield et al., Learning Styles and Pedagogy in Post-16 Learning: A Systematic and Critical Review (London: Learning \& Skills Research Centre, 2004).

11. Daniel T. Willingham, Why Don't Students like School? A Cognitive Scientist Answers Questions about How the Mind Works and What It Means for the Classroom, 1st ed. (San Francisco, CA: Jossey-Bass, 2009). 147

12. Daniel Willingham and David Daniel, "Teaching to What Students Have in Common," Educational Leadership 69, no. 5 (February 2012): 21.

13. Cedar Riener and Daniel T. Willingham, "The Myth of Learning Styles," Change (October 2010).

14. Pashler et al., Organizing Instruction and Study to Improve Student Learning; Willingham and Daniel, "Teaching to What Students Have in Common"; Dunlosky et al., "Improving Students' Learning With Effective Learning Techniques."

15. Harry F. Harlow, Margaret Kuenne Harlow, and Donald R Meyer, "Learning Motivated by a Manipulation Drive," Journal of Experimental Psychology 40, no. 2 (April 1950): 228-34; Daniel H. Pink, Drive: The Surprising Truth about What Motivates Us (New York: Riverhead Books, 2009).

16. Willingham, Why Don't Students like School? 21.

17. Paul J. Silvia, "Interest-The Curious Emotion," Current Directions in Psychological Science 17, no. 1 (February 2008): 57-60.

18. Willingham, Why Don't Students like School?, 54; Doyle and Zakrajsek, The New Science of Learning. 74

19. David Kember, Amber Ho, and Celina Hong, "The Importance of Establishing Relevance in Motivating Student Learning," Active Learning in Higher Education 9, no. 3 (November 1, 2008): 249-63.

20. Mayer and Wittrock, "Problem Solving," 289; Karen Murphy and Patricia A. Alexander, Understanding How Students Learn: A Guide for Instructional Leaders, Leadership for Learning (Thousand Oaks, CA: Corwin, 2006), 41.

21. Amy Van Epps and Megan Sapp Nelson, "One-Shot or Embedded? Assessing Different Delivery Timing for Information Resources Relevant to Assignments," Evidence Based Library and Information Practice 8, no. 1 (n.d.).

22. George A. Miller, "The Magical Number Seven, Plus or Minus Two: Some Limits on Our Capacity for Processing Information," Psychological Review 63 (1956): 81-97. 
23. Alan Baddeley, "The Magical Number Seven: Still Magic After All These Years?," Psychological Review 101, no. 2 (April 1994): 353-56; Nelson Cowan, "The Magical Number 4 in ShortTerm Memory: A Reconsideration of Mental Storage Capacity," Behavioral and Brain Sciences 24, no. 1 (February 2001): 87-114; Fernand Gobet and Gary Clarkson, "Chunks in Expert Memory: Evidence for the Magical Number Four . . . or Is It Two?," Memory 12, no. 6 (November 2004): 732-47.

24. John Sweller, "Cognitive Load During Problem Solving: Effects on Learning," Cognitive Science 12, no. 2 (1988): 257-85; Paul Chandler and John Sweller, "Cognitive Load Theory and the Format of Instruction," Cognition and Instruction 8, no. 4 (1991): 293-332.

25. David Bawden and Lyn Robinson, "The Dark Side of Information: Overload, Anxiety and Other Paradoxes and Pathologies," Journal of Information Science 35, no. 2 (April 2009): 180-91.

26. Joel Rudd and Mary Jo Rudd, "Coping with Information Load: User Strategies and Implications for Librarians," College $\&$ Research Libraries 47, no. 4 (July 1986): 315-22.

27. Willingham, Why Don't Students like School? 14.

28. Brian Boyd, On the Origin of Stories: Evolution, Cognition, and Fiction (Cambridge, MA: Harvard Belknap, 2010); Jonathan Gottschall, The Storytelling Animal: How Stories Make Us Human (Boston: Houghton Mifflin Harcourt, 2012).

29. Willingham, Why Don't Students like School?, 66.

30. Joan Didion, "The White Album," in The White Album: Essays (New York: Farrar, 1979), 11-50.

31. Stephen N. Elliott, Thomas R. Kratochwill, and Joan Littlefield Cook, Educational Psychology: Effective Teaching, Effective Learning, 3rd ed. (Boston: McGraw Hill, 2000). See also Daniel Willingham, "Making Students More CURIOUS," Knowledge Quest 42, no. 5 (May 2014): 32. In addition to increasing information retention, this methodology, by demonstrating the instructor's curiosity with research, can facilitate students' curiosity and cognitive engagement.

32. Jody Rosen, "Rosen on Drake's Nothing Was the Same: Is Drake the Rap-Game Taylor Swift?," Vulture, September 24, 2013, www.vulture.com/2013/09/music-review-drake-nothing-was -the-same.html.

33. Yvonne Nalani Meulemans and Allison Carr, "Not at Your Service: Building Genuine Faculty-Librarian Partnerships," Reference Services Review 41, no. 1 (2013): 80-90.

34. Katy Waldman, "Haters Gonna Hate, Study Confirms," The XX, August 28, 2013, www.slate.com/blogs/xx_factor/ 2013/08/28/haters_are_gonna_hate_dispositional_attitude _study_confirms_it.html.
35. Mayer and Wittrock, "Problem Solving," 295.

36. Diana J Arya and Andrew Maul, "The Role of the Scientific Discovery Narrative in Middle School Science Education: An Experimental Study," Journal of Educational Psychology 104, no. 4 (November 2012): 1022-32.

37. Ibid. 124 .

38. Ibid. 124

39. Ibid. 122

40. Willingham, Why Don't Students like School?

41. "Polo Shirt," Wikipedia, August 16, 2014, http://en.wikipedia .org/wiki/Polo_shirt.

42. Pashler et al., Organizing Instruction and Study to Improve Student Learning.

43. Don Fallis, "On Verifying the Accuracy of Information: Philosophical Perspectives," Library Trends 52, no. 3 (2004): 463-87.

44. Pashler et al., Organizing Instruction and Study to Improve Student Learning, 30.

45. Fallis, "On Verifying the Accuracy of Information."

46. The CRAAP test has students evaluate information by its currency, relevance, authority, accuracy, and purpose: www.csuchico.edu/ lins/handouts/eval_websites.pdf.

47. Barak Rosenshine, Carla Meister, and Saul Chapman, "Teaching Students to Generate Questions: A Review of the Intervention Studies," Review of Educational Research 66, no. 2 (January 1, 1996): 181-221; Scotty D. Craig et al., "The Deep-Level-Reasoning-Question Effect: The Role of Dialogue and Deep-LevelReasoning Questions during Vicarious Learning," Cognition $\&$ Instruction 24, no. 4 (2006): 565-91; Pashler et al., Organizing Instruction $\&$ Study to Improve Student Learning.

48. Henry L. Roediger and Andrew C. Butler, "The Critical Role of Retrieval Practice in Long-Term Retention," Trends in Cognitive Sciences 15, no. 1 (2011): 20-27.

49. Angela L. Duckworth et al., "Deliberate Practice Spells Success: Why Grittier Competitors Triumph at the National Spelling Bee," Social Psychological and Personality Science 2, no. 2 (March 1, 2011): 174-81.

50. K. Anders Ericsson, Ralf Th. Krampe, and Clemens Teschromer, "The Role of Deliberate Practice in the Acquisition of Expert Performance," Psychological Review 100, no. 3 (1993): 363-406.

51. Malcolm Gladwell, Outliers: The Story of Success, 1st ed (New York: Little, Brown, 2008).

52. Willingham, Why Don't Students like School?; Pashler et al., Organizing Instruction and Study to Improve Student Learning.

53. Doyle and Zakrajsek, The New Science of Learning. 72. 